\title{
Hydrodynamics of a Three-phase Airlift Reactor with an Enlarged Separator - Application to High Cell Density Systems
}

\author{
Jaroslav Klein, António A. Vicente and José A. Teixeira
}

*Centro de Engenharia Biológica - IBQF, Universidade do Minho, 4710-057 Braga, Portugal

$\mathrm{C}$ ontinuous three-phase biosystems with high solid volume fractions (known as high cell density systems), where cells (biocatalysts) are immobilized in/on a carrier, show very interesting advantages when compared to standard suspended cell batch processes: high biocatalyst concentration resulting in high conversion rates; use of the same biocatalyst for extended time periods; easy separation of the biocatalyst from the liquid phase. High cell density systems (HCDS), operating continuously are clearly one of the most promising techniques to increase the productivity of biotechnological processes (Vicente et al., 2001). Among several bioreactor designs available, airlift (ALR) systems are one of the most suitable to operate with high solids concentration due to the advantageous combination of sufficient suspension of solids and mixing and controlled shear stress. Particularly for continuous HCDS, an internal-loop airlift reactor with a enlarged separator may provide an efficient retention of solid phase inside the reactor.

In the literature, principally two different types of particles are commonly used in three-phase airlift (TPAL) systems - high-density and low-density particles. High-density particles are exploited mainly in chemical technology (Douek et al., 1994), and low-density particles (with similar density as water) are used mostly in biotechnology as immobilized or flocculating cells systems (Birch and Boraston, 1988; Pollard et al., 1996; Domingues et al., 1999; Sun et al., 1999). The density of these particles is slightly higher than the density of water and ranges usually from 1015 to $1600 \mathrm{~kg} / \mathrm{m}^{3}$.

For such low-density particles, the liquid (L) and solid (S) phases are often assumed as one pseudohomogeneous L-S phase. Tobajas et al. (1999) studied the solids distribution in TPAL systems (marine sediments with particle diameter less than $0.850 \mathrm{~mm}$ and density of $2200 \mathrm{~kg} \cdot \mathrm{m}^{-3}$ were used as a solid phase) with different downcomer to riser cross-sectional area ratio $A_{D} / A_{R}$ and solids loading. They observed the existence of uniform axial distribution of solids in the riser and downcomer, which is independent of the $A_{D} / A_{R}$ ratio and of the solid concentration. The work of Freitas and Teixeira (1998) investigated the low-density solids (alginate particles with a diameter of cca $2 \mathrm{~mm}$ and with densities of 1023 and $1048 \mathrm{~kg} \cdot \mathrm{m}^{-3}$ ) distribution in a TPAL with an enlarged degassing zone. However, they discovered the existence of an axial and a radial distribution of the solid phase with similar solids holdups both in riser and

\footnotetext{
*Author to whom correspondence may be addressed. E-mail address: jateixeira@ deb.uminho.pt
}

The hydrodynamic study of a three-phase airlift reactor with an enlarged head zone was carried out. Effects of gas-solid-liquid separator design and riser to downcomer cross-sectional area using different lengths and diameters of the draft tube were investigated. Ca-alginate beads with entrapped yeast biomass at different loadings up to $21 \%(\mathrm{v} / \mathrm{v})$ were used in order to mimic the solid phase of conventional high cell density systems. The main hydrodynamic parameters - liquid circulation velocity, gas and solids holdups in all reactor sections have been measured and experimental values were satisfactorily predicted using an appropriate three-phase model. The results of this study may be applied to suggest the optimal design (in terms of hydrodynamic behaviour) of a batch/continuous three-phase ALR for high cell density fermentations.

On a mené une étude hydrodynamique d'un réacteur airlift triphasique ayant une zone de tête élargie. On a étudié les effets de la conception des séparateurs gaz-solide-liquide et de la section transversale entre la colonne montante et le déversoir avec différents diamètres et longueurs du tube d'aspiration. Des billes d'alginate de calcium avec de la biomasse de levure piégée à différents taux de charge jusqu'à des taux de charge de $21 \%$ en volume ont été employées afin d'imiter la phase solide de systèmes à forte masse volumique de cellules. Les principaux paramètres hydrodynamiques - la vitesse de circulation du liquide, les rétentions de gaz et de solides dans toutes les sections du réacteur ont été mesurés et les valeurs expérimentales sont prédites de manière satisfaisante à l'aide d'un modèle triphasique approprié. Les résultats de cette étude peuvent servir à éatblir la conception optimale (en termes de comportement hydrodynamique) d'un réacteur airlift triphasique discontinu/continu pour des fermentations à forte masse volumique de cellules.

Keywords: airlift, three-phase flow, hydrodynamic model, solids distribution, gas-liquid separator. 
downcomer sections. Solids holdup increased, in general, from the wall to the middle of the degassing zone and from the top to the bottom of the reactor.

Recently, several three-phase models have been developed to predict the hydrodynamics of internal/external-loop airlift reactors. Two groups of models can be distinguished: the first group assumes the existence of a pseudohomogeneous L-S phase with uniform solids distribution throughout the reactor and the reactor hydrodynamics was treated only by extended two-phase models, (Lu et al., 1995; Heijnen et al., 1997; Hwang and Lu, 1997; Freitas et al., 1999). The average overall solids holdup is thus calculated from the total solids loading. The second group implies uneven solids distribution and the equations for the solids distribution between the riser and downcomer sections are incorporated into the model, (Livingston and Zhang, 1993; Douek et al., 1994; García-Calvo et al., 1999).

Despite all these models, (to our knowledge) none of them considers the hydrodynamics of a batch/continuous threephase airlift reactor with significantly enlarged separator. The results of the work of Freitas (1998) and the experimental data obtained at the present work indicate that an uneven solids distribution can exist in the ALR with an enlarged separator zone, even for low-density particles. Since low gas flow rates are frequently used in fermentation technology (often up to 0.1-0.4 vvm), the inhomogenity of solids distribution throughout the bioreactor can be an inevitable phenomenon. Having this in mind, the model, which takes into account the solids distribution between the riser and downcomer sections, should be used to predict the hydrodynamics in a three-phase airlift reactor with low-density particles.

This work aims at characterizing the influence of the design of an enlarged separator as well as the influence of riser to downcomer cross-sectional area ratio $\left(A_{D} / A_{R}\right)$ on the hydrodynamics of a three-phase (G-L-S) internal-loop ALR. An appropriate hydrodynamic model was adapted and used to fit the hydrodynamic data, where the effects of solids loading and air flow rate on the gas and solid distribution in all the reactor sections and on liquid velocity in the riser and downcomer are described.

\section{Hydrodynamic Model}

The TPAL model suggested by García-Calvo et al. (1999) was used with modifications. The energy balance in combination with the momentum balance and solids distribution equations is applied to predict the riser holdup and liquid velocity. The model assumes the density of the pseudohomogeneous L-S phase, $\rho_{H}$, and absence of gas in the downcomer. The latter fact is taken into account in the model assuming the gas behaviour in the riser to be similar to that in a bubble column. The fit of experimental data attained from the ALR with a strong gas recirculation and enlarged head zone (Heijnen et al., 1997) presented in the work of García-Calvo et al. clearly demonstrated the feasibility of this method.

The model describes three three-phase flow regimes in relation to the solids behaviour as the gas flow rate increases - the packed bed mode without suspension of particles and no liquid circulation, the fluidized bed mode with particle suspension exclusively in the riser zone and nonzero liquid circulation and the circulated bed mode with solids distribution throughout the reactor.
The final equation of the energy balance is:

$$
\begin{aligned}
& p_{c} U_{G c} \ln \left(1+\frac{\rho_{H R} g H_{D T}}{p_{a t m}}\right) \\
& =\frac{1}{2}\left[\alpha K_{f R} \rho_{H R}\left(\frac{A_{D}}{A_{R}}\right)^{2}=K_{f D} \rho_{H D}\right]\left(\frac{A_{D}}{A_{R}}\right)\left(1-\varepsilon_{S D}\right)^{3} V_{L D}^{3} \\
& +\frac{0,64(2)^{3 N / 2} N^{3} \rho_{H R} H_{D T}\left(V_{L O}-\bar{V}_{L R}\right)^{3}}{D_{R}} \\
& \times\left(\frac{1}{2(3 N-1)}+\frac{1}{3 N+1}-\frac{2^{1 / 2}}{3 N}\right)+\varepsilon_{G R} U_{b} \rho_{H R} g H_{D T}
\end{aligned}
$$

The first term of RHS is equal to zero in the packed bed mode. If a pseudohomogeneous L-S phase within the riser and the downcomer zones is assumed, the phase density can be expressed as follows:

$$
\begin{aligned}
& \rho_{H R}=\frac{\left(1-\varepsilon_{G R}-\varepsilon_{S R}\right) \rho_{L}+\varepsilon_{S R} \rho_{L}}{\left(1-\varepsilon_{G R}\right)} \\
& \rho_{H D}=\left(1-\varepsilon_{S D}\right) \rho_{L}+\varepsilon_{S D} \rho_{S}
\end{aligned}
$$

The momentum balance applied to the three-phase flow in an airlift reactor is written as:

$$
\begin{aligned}
& {\left[\varepsilon_{G R}-\left(\frac{\rho_{S}}{\rho_{L}}-1\right)\left(\varepsilon_{S R}-\varepsilon_{S D}\right)\right] g H_{D T} \rho_{L}} \\
& =\frac{1}{2}\left[\alpha K_{f R} \rho_{H R}\left(\frac{A_{D}}{A_{R}}\right)^{2}+R_{f D} \rho H D\right]\left(1-\varepsilon_{S D}{ }^{2} V_{L D}^{3}\right)
\end{aligned}
$$

The riser gas holdup $\varepsilon_{G R}$ is determined by equation:

$$
\varepsilon_{G R}=\frac{U_{G C}}{U_{b}+\frac{\left(V_{L O}-\bar{V}_{L R}\right)}{2\left(1-\varepsilon_{G R}-\varepsilon_{S R}\right)}\left(\frac{N}{N+2}\right)+V_{L R}}
$$

The solids distribution between the riser and downcomer is calculated according following equations, in terms of the solids holdup defining the $\varepsilon_{S}{ }^{0}$ as the solids holdup in the riser when all particles are there:

$$
\begin{aligned}
& \varepsilon_{S R}=\varepsilon_{S}^{0} \frac{V_{L D+U_{t}}}{V_{L D}+V_{L R}} \\
& \varepsilon_{S D}=\varepsilon_{S}^{0} \frac{A_{R}}{A_{D}} \frac{V_{L R+U_{t}}}{V_{L D}+V_{L R}}
\end{aligned}
$$

Determination of boundary conditions between three-phase flow regimes is crucial for accurate description of the TPAL hydrodynamics (García-Calvo et al., 1999). The transition from packed bed mode onto the fluidized bed mode occurring if the 
following condition is valid:

$\varepsilon_{G R}-\left(\frac{\rho_{S}}{\rho_{L}}-1\right) \varepsilon_{S}^{00} \geq 0$

The onset of the circulated bed mode appears, if the following holds true:

$V_{L R} \geq U_{t}$

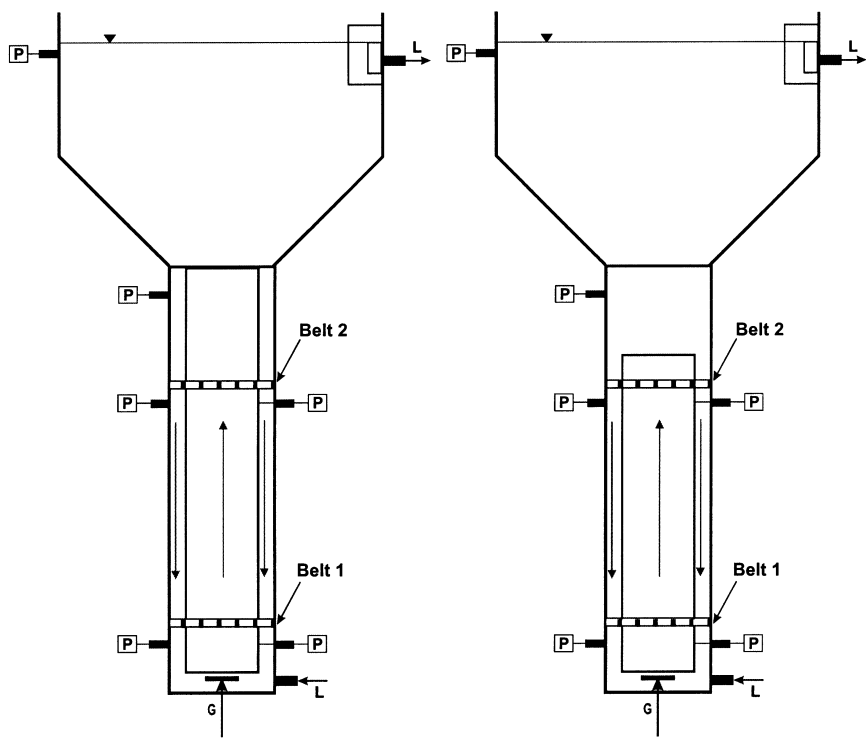

Figure 1. Scheme of the airlift reactor. Belts 1 and 2 indicate the position of the measuring coils for the velocity measurement by the magnetic tracer method. P: Manometer taping, L - liquid phase, G gas phase. A) Configuration 1DT - ALR with simple separator; B) Configurations 2DT and 3DT - ALR with dual separator.
The model equations of energy (Equation 1) and momentum (Equation 4) balance, gas holdup ( Equation5) and solids distribution (Equations 6 and 7) have to be solved by an iteration procedure to calculate the hydrodynamic parameters $V_{L D^{\prime}} \varepsilon_{G^{\prime}} \varepsilon_{S R}$ and $\varepsilon_{S D}$

\section{Materials and Methods \\ The Reactor Set-up}

A $50 \mathrm{~L}$ internal-loop ALR with an enlarged degassing zone was used for hydrodynamic measurements with three inner tubes of different diameters and lengths labelled as 1DT, 2DT and 3DT (Figure 1). The basic dimensions of the reactor and variations of the configurations are listed in Table 1. The head section has the shape of a reversed cut cone with a cylindrical overhead. The conical section forms a $51^{\circ}$ angle with the main body of the reactor. The reactor was basically designed to be used in a continuous operation; a drainage tube for liquid overflow and a local settler were positioned at the reactor wall to keep the volume level constant at 50 litres. The reactor operated both in batch and continuous modes. A water flow rate of $30 \mathrm{~L} / \mathrm{h}$ was applied during the continuous operation corresponding to a dilution rate of $0.6 \mathrm{~h}^{-1}$.

In the airlift reactor with an enlarged head zone, different separator configurations can be easily achieved only by adjusting the length of the draft tube. Two basic constructions of the ALR were considered:

The top of the draft tube is located exactly at/above the opening of the enlarged zone; in this case the separator consists only of the enlarged section (Figure 1a). Such reactor configuration is entitled the airlift reactor with simple enlarged separator (label 1DT).

The top of the draft tube is located below the opening of the enlarged zone inside the downcomer column; in this case the separator consists of two parts (Figure 1b) - an upper enlarged zone acting as the particle settler and a lower narrow part with high mixing intensity, which mainly determine on a bubbles retention inside the reactor. This configuration of the head zone was entitled "dual" separator (labels 2DT and 3DT).

Table 1. Basic characteristics of ALR used in experiments.

$D_{C}$ - column diameter, $D_{R}$ - riser draft tube diameter, $A_{R}$ - riser cross-sectional area, $A_{D}$ - downcomer cross-sectional area, $H_{D T}-$ height of the draft tube, $H_{T}$ - height of liquid level above the top of draft tube, $D_{S E P}$ - diameter of separator zone, $H_{D T} / H_{C}-$ ratio of the draft tube to the height of narrow part of column, $L_{e R}$ - equivalent length of the fittings in the riser, $L_{e D}$ - equivalent length of the fittings in the downcomer.

\begin{tabular}{|c|c|c|c|c|c|c|c|c|c|}
\hline Label & $\begin{array}{c}D_{C} \\
(\mathrm{~mm}) \\
\end{array}$ & $\begin{array}{c}D_{R} \\
(\mathrm{~m})\end{array}$ & $\begin{array}{c}A_{D} / A_{R} \\
(-)\end{array}$ & $\begin{array}{l}H_{D t} \\
(\mathrm{~m}) \\
\end{array}$ & $\begin{array}{l}H_{T} \\
(\mathrm{~m}) \\
\end{array}$ & $\begin{array}{l}D_{\text {SEP }} \\
(\mathrm{m})\end{array}$ & $\begin{array}{c}H_{D T} / H_{C} \\
(-)\end{array}$ & $\begin{array}{l}L_{e R} \\
(\mathrm{~m})\end{array}$ & $\begin{array}{l}L_{e D} \\
(\mathrm{~m}) \\
\end{array}$ \\
\hline 1DT & $142 / 150$ & $92 / 100$ & 1.20 & 1.4 & 0.292 & 0.442 & 1.00 & 10 & 3.5 \\
\hline 2DT & $142 / 150$ & $92 / 100$ & 1.20 & 1.2 & 0.492 & 0.442 & 0.86 & 12 & 4.8 \\
\hline 3DT & $142 / 150$ & $62 / 70$ & 3.97 & 1.2 & 0.492 & 0.442 & 0.86 & 13.9 & 11.6 \\
\hline
\end{tabular}

Table 2. Average values of portion of solids volume in individual sections to the total volume of solids in the $A L R, V_{S R, D, S} / V_{S t o t}($ in $\% v / V$ ).

\begin{tabular}{cccccccccc}
\hline $\begin{array}{c}\text { Label } \\
\phi_{\text {Stot }}\end{array}$ & Riser & $\begin{array}{c}\text { 1DT } \\
\text { Downcomer }\end{array}$ & Separator & Riser & $\begin{array}{c}\text { 2DT } \\
\text { Downcomer }\end{array}$ & Separator & $\begin{array}{c}\text { 3DT } \\
\text { Riser }\end{array}$ & $\begin{array}{c}\text { Downcomer } \\
\text { Separator }\end{array}$ \\
\hline $7 \%$ & 26 & 36 & 38 & 20 & 23 & 57 & 13 & 41 \\
$14 \%$ & 38 & 40 & 22 & 24 & 28 & 48 & 19 & 51 \\
$21 \%$ & 30 & 26 & 44 & 25 & 24 & 51 & 16 & 53 \\
\end{tabular}



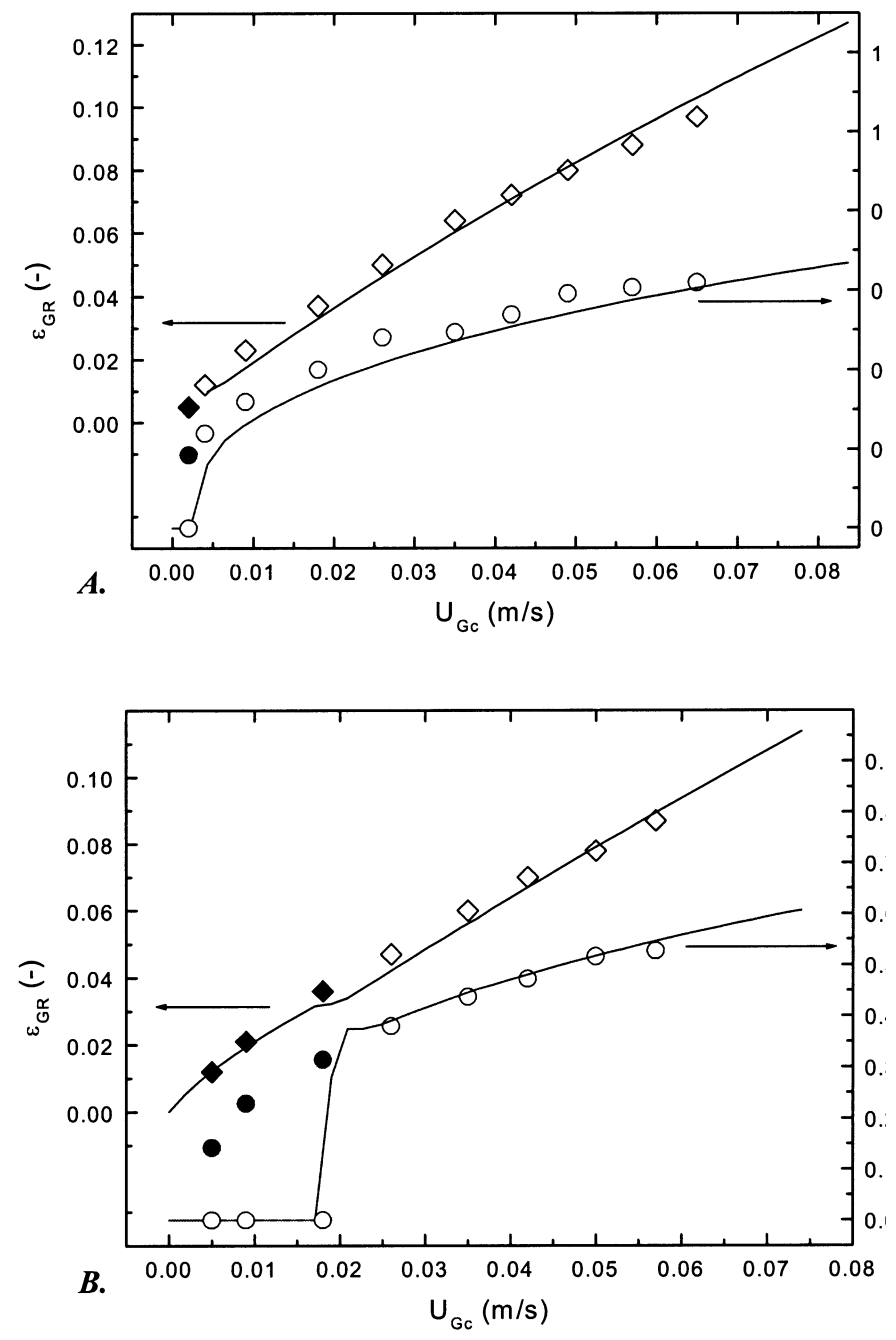

Figure 2. Model prediction of experimental values of the riser gas holdup $\left(\varepsilon_{G R}\right)$ and linear liquid velocity in the downcomer $\left(V_{L D}\right)$. Solid and open symbols present measurements performed by decreasing and increasing of $U_{G c}$, respectively. A) ALR configuration 1DT with solids loading $\left.\phi_{\text {Stot }}=7 \%(\mathrm{v} / \mathrm{v}), \mathrm{B}\right)$ ALR configuration 2DT with solids loading $\phi_{\text {Stot }}=21 \%(\mathrm{v} / \mathrm{v})$.

The difference between 2DT - 3DT reactor sets is in different downcomer to riser cross-sectional area ratio, $A_{D} / A_{R}$.

In all the experiments, water and air were used as the liquid and gas phases, respectively. The experiments were carried out at the average temperature of $19{ }^{\circ} \mathrm{C}$ and atmospheric pressure. The air injection was made $0.061 \mathrm{~m}$ below the bottom of the draft tube by means of a perforated plate with a diameter of $0.03 \mathrm{~m}$, with 30 holes of $1 \mathrm{~mm}$ each. The air flow rate, $Q_{\mathrm{G}^{\prime}}$ was controlled by means of rotameters and ranged from 2 up to 70 $\mathrm{L} / \mathrm{min}$ (referred to $1 \mathrm{~atm}$ and $20^{\circ} \mathrm{C}$ ), covering most flow rates applied in fermentation processes (0.04-1.4 vvm). In the present work, the air flow rate is given as the characteristic superficial velocity, $U_{G c^{\prime}}$ referred to the column diameter, $D_{C}$, in order to enable a correct comparison of ALR configurations with different cross-sectional area ratios, $A_{D} / A_{R}$. The parameter $U_{G c}$ was calculated for the conditions in the geometric centre of the column.

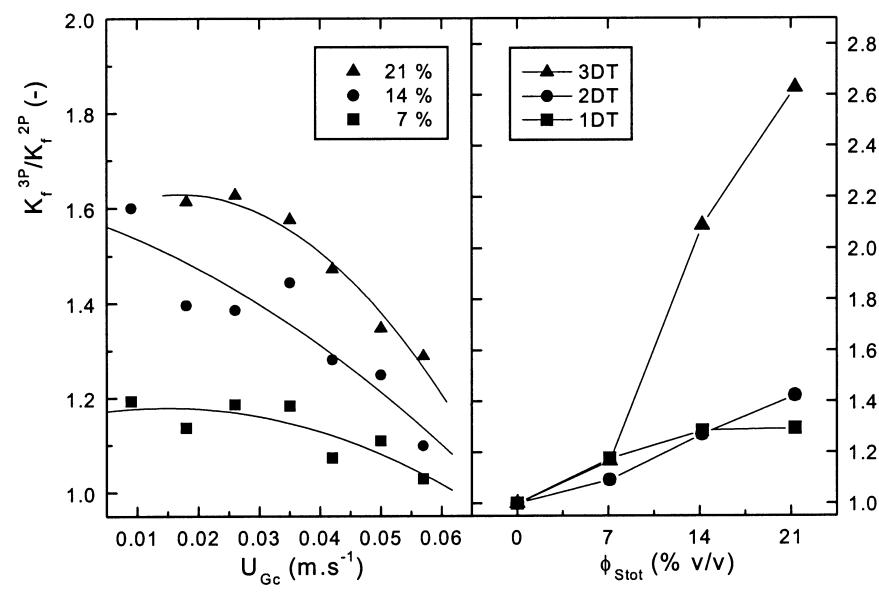

Figure 3. Variation of overall friction coefficient in three-phase flow $\left(K_{f}^{3 P}\right)$ compared to the one in the two-phase system $\left(K_{f}^{2 P}\right)$ as a function of gas superficial velocity $U_{G c}$ (reactor 2DT) and solids loading $\phi_{S t o t}$. For meanings of labels of the reactor configurations 1DT, 2DT and 3DT, see Table 1.

\section{Solid Phase}

Ca-alginate beads with immobilized cells were used as solid phase, which mimic immobilizing carriers or yeast flocs. They have been prepared according to the procedure described by Vicente and Teixeira (1995). Ca-alginate beads, prepared with an addition of dead compressed baker's yeasts, had a mean diameter of $2.15 \pm 0.13 \mathrm{~mm}$ and density of $1048 \pm 1 \mathrm{~kg} \cdot \mathrm{m}^{-3}$. Three different solids loadings were used: 7, 14 and $21 \%(\mathrm{v} / \mathrm{v})$ (Table 2).

\section{Liquid Velocity Measurement}

A magnetic tracer method (Klein et al., 2000) was used to determine the liquid velocity in the internal-loop ALR. The method makes use of a flow following technique in combination with a magnetic metal locator. A magnetic particle with a high magnetic permeability and a diameter of $11 \mathrm{~mm}$ was used as the flow follower. The particle density was practically equal to the liquid density, resulting in a very low terminal settling velocity (up to $1 \mathrm{~cm} \cdot \mathrm{s}^{-1}$ ), when compared to the magnitude of liquid velocities achieved in the reactor. The measuring technique allows the determination of the liquid velocity, the mean circulation velocity and the residence time of the flow follower in individual sections of the airlift reactor.

\section{Gas and Solids Holdup Measurement}

A method for simultaneous measurement of gas and solids holdups in gas-liquid-solid (G-L-S) multiphase contactors was used (Wenge et al., 1995). This method was chosen because of its advantageous use in three-phase fermentation systems, where a direct outside contact with the fermentation broth should be avoided as much as possible because of contamination risks. The method makes use of measurements of hydrostatic pressure in the three-phase dispersion followed by interruption of gas flow, complete gas disengagement, and a second measurement in the resulting two-phase (solid-liquid) dispersion. This measurement period has to be short enough to avoid 


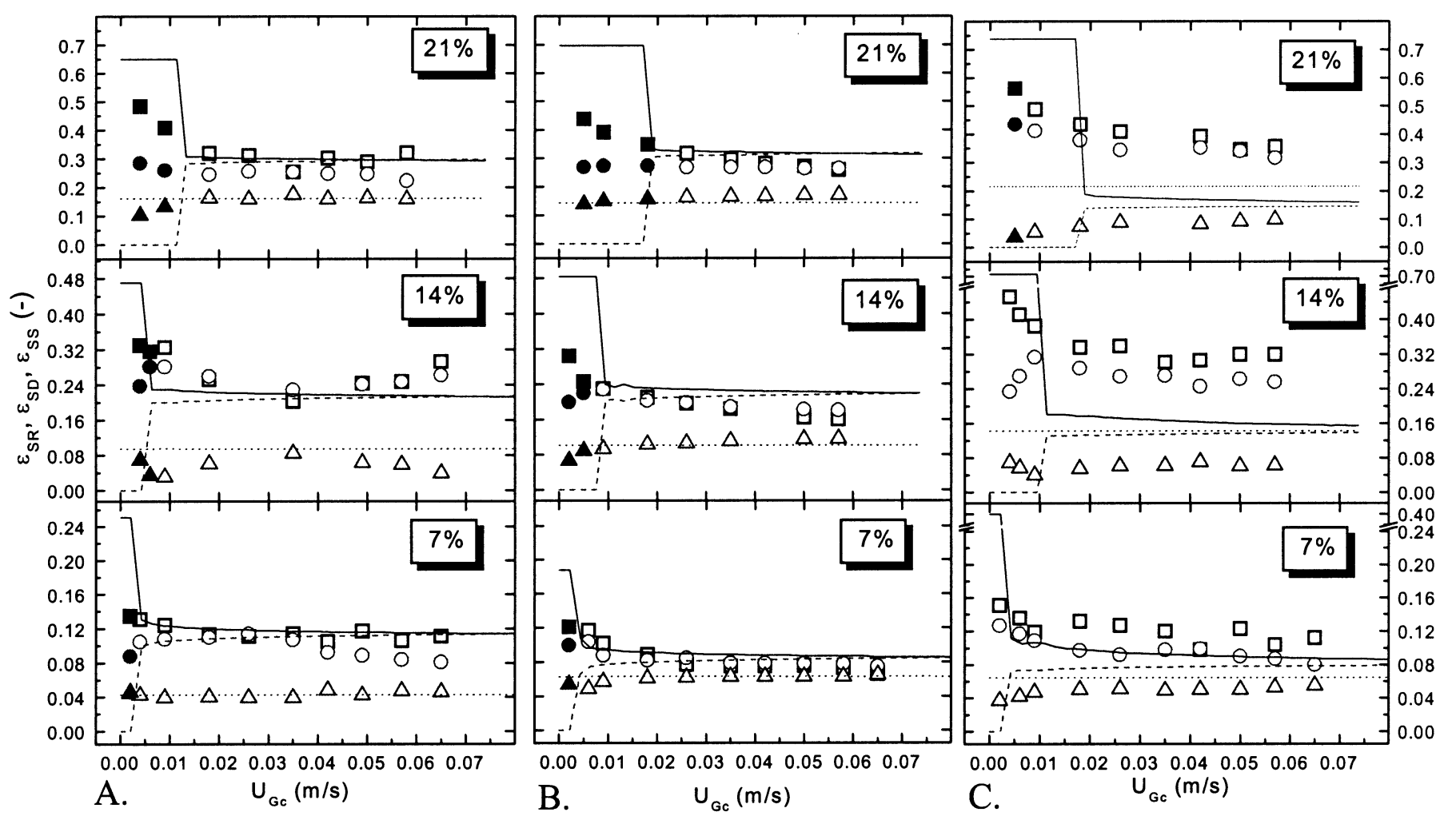

Figure 4. Experimental and predicted values of the solids holdup in riser ( $\square$, solid line), downcomer ( $\odot$, dash line) and separator ( $\triangle$, dot line) sections of the ALR for solids loadings of $7 \%, 14 \%$ and $21 \%(\mathrm{v} / \mathrm{v})$. A) ALR configuration 1DT, B) ALR configuration 2DT, C) ALR configuration 3DT (see also Table 1). Solid and open symbols present measurements performed by decreasing and increasing of $U_{G c}$, respectively.

significant sedimentation of the solid particles. Quick-response differential pressure transducers (Shaewitz Sensors, USA) were used for manometric measurements of pressure differences between two places in the riser, downcomer and separator of the ALR (Figure 1). The signal from the pressure sensors was sampled once per second and the data were collected by PC through a standard data acquisition system. The positions of the measuring points were properly chosen in order to avoid the effect of liquid acceleration at the bottom and at the top of the draft tube (Merchuk et al., 1994). A lower pressure tap for measurements in the separator zone was situated $2 \mathrm{~cm}$ below an edge of conical enlarged zone, therefore holdup measurements in the separator include only its upper enlarged part.

\section{Results and Discussion}

Before hand, several comparative measurements were carried out in batch and continuous systems with both a G-L and G-L$S$ flows to evaluate the effect of the mode of reactor operation on its hydrodynamic behaviour. A dilution rate as high as 0.6 $\mathrm{h}^{-1}$ was applied to the continuous system, which represents a conventional upper limit in high cell density systems ensuring both an ability of operation and economic feasibility of the bioprocess (Domingues et al., 2001). The results did not show any relevant differences in the values of all principal hydrodynamic parameters. In fact, as compared to the magnitude of the liquid circulation velocities typically attained, the inlet flow of liquid substrate represents a very small contribution (up to $0.8 \%$ ) to the total fluid flow rate in the reactor. It means that the prediction of the hydrodynamics of the continuous TPAL reactor can be satisfactorily treated by model equations derived from the batch ALR systems. Therefore, all experimental data presented in this work have been obtained using the batch system.

\section{Assessment of Model Parameters}

The solution of the model equations involves, apart from the knowledge of reactor geometry, the properties of all phases being employed. The number $N$ representing the liquid velocity profile parameter was assumed to be equal to 2 corresponding to a parabolic profile.

\section{Particle Settling Velocity $U_{t}$}

The settling velocity of a particle in a multiphase dispersion is usually considered to differ from the terminal settling velocity in a stagnant water pool, $U_{t \infty}$. García-Calvo et al. (1999) suggested an equation for the calculation of the settling velocity in a multiphase (G-L-S) fluid. According to this expression, the velocity $U_{t}$ is assumed to decrease with both solids and gas holdup. This equation holds for $R e_{p}>150$. However, for lower values, the interactions among particles and the particles interactions with bubbles do not affect particle settling. For alginate particles with low density, $R e_{p}$ value (around 70 ) is low enough to assume the settling velocity $U_{t}$ equal to the $U_{t \infty}$. The value of the terminal settling velocity was measured to be equal to $0.0296 \mathrm{~m} . \mathrm{s}^{-1}$ and verified by calculation (Perry and Green, 1985). 


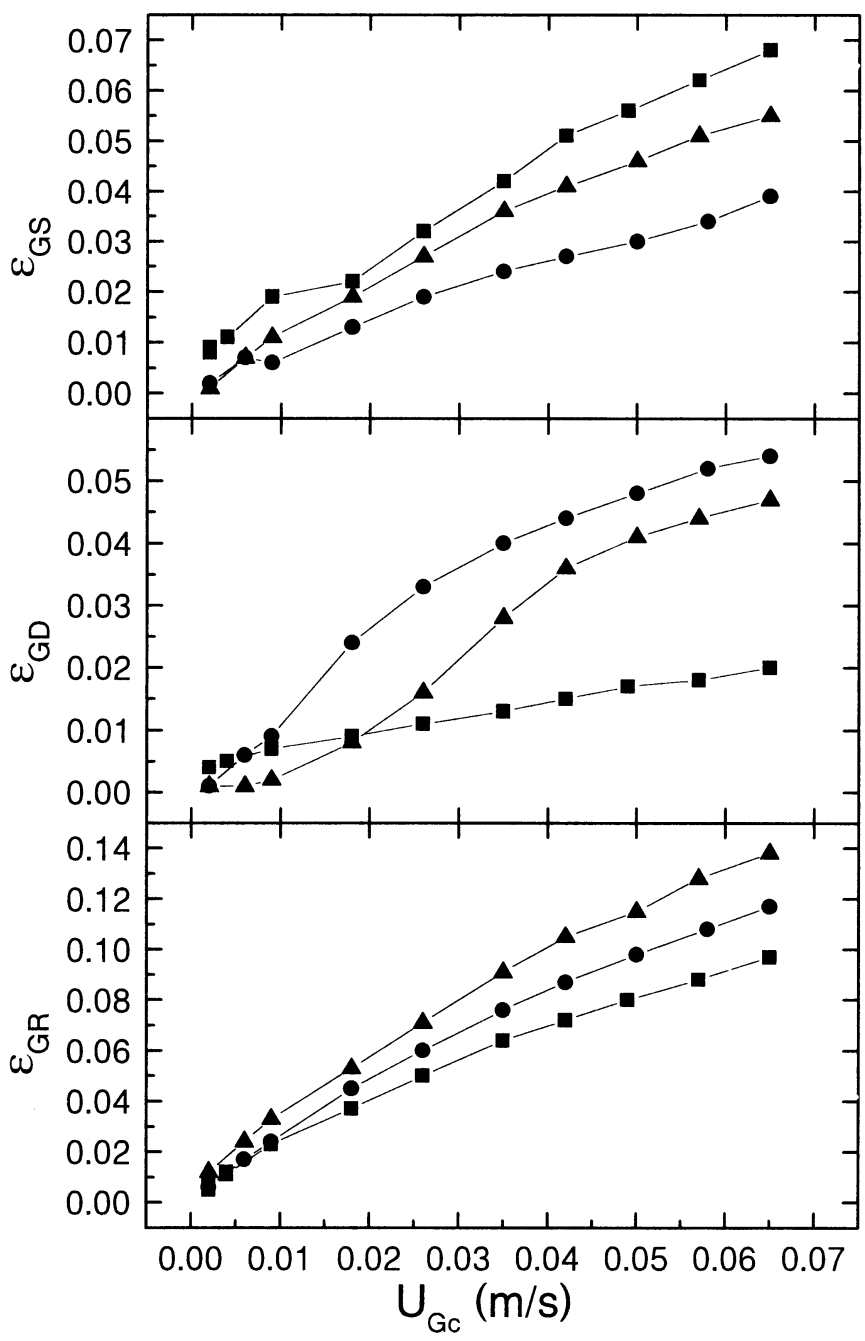

Figure 5. Effect of the area ratio $A_{D} / A_{R}$ and separator design on the partial gas holdups for solids loading $\phi_{\text {stot }}$ equal to $7 \%(\mathrm{v} / \mathrm{v})$. Reactor set 1DT $(\boldsymbol{\bullet})$, reactor set 2DT $(\bullet)$, reactor set 3DT $(\boldsymbol{\Lambda})$. For meanings of labels of the reactor sets, see Table 1.

\section{Bubble Rise Velocity $U_{b}$}

In air-water systems it is widely accepted in the literature that the equilibrium diameter of a gas bubble in stagnant water is 6 $\mathrm{mm}$ with its rise velocity, $U_{b^{\prime}}$ equal to $0.25 \mathrm{~m} . \mathrm{s}^{-1}$ (Heijnen and van't Riet, 1984). The assessment of the impact of the solid phase on the bubbles was done through the Weber number, We, (Epstein, 1981), which is a numerical criterion for examination of the bubble break-up and coalescence events. In the presented case, the We value was found to be around 2.1, thus neither breaking-up nor coalescence significantly dominate. Therefore, the value of the bubble rise velocity equal to $0.25 \mathrm{~m} . \mathrm{s}^{-1}$ was used for all three-phase experiments.

\section{Friction Coefficient $K_{f}$}

The determination of $K_{f}$ was done using a procedure suggested by García-Calvo et al. (1999). It utilizes the Fanning equation with equivalent lengths of the reactor fittings separately for the riser $\left(L_{e R}\right)$ and downcomer $\left(L_{e D}\right)$ sections obtained from the Blasius equation for one-phase turbulent flow. The variation of the friction losses due to the presence of gas phase was expressed by introducing the parameter $\alpha$ in the riser friction term $K_{f R}$. The friction coefficient can be expressed finally as follows:

$K_{f i}=0.32\left[\frac{D_{i}^{5} U_{L i} \rho_{H i}}{\mu_{H i}}\right]^{-1 / 4} L_{e i}$

Here $i$ means either riser or downcomer sections. $\mu_{H i}$ is the viscosity of the pseudohomogeneous phase calculated using an experimental correlation (Lu et al., 1995). The total friction coefficient $K_{f}$ is calculated as a sum of riser and downcomer friction coefficient contributions.

The estimated values of $L_{e R}$ and $L_{e D}$ are listed in Table 1.

\section{Initial Riser and Separator Solids Holdups}

The model requires the assessment of the solids holdup initially presented in the riser $\varepsilon_{S}{ }^{00}$ for an accurate determination of a minimum gas flow velocity $U_{G \text { min }}$ at the stalling point. The $\varepsilon_{S}{ }^{00}$ values have been determined according to the reactor bottom geometry (García-Calvo et al., 1999). An important fact, which was never pointed out in the available literature, is the quantification of the solids presence in the separator zone. Especially in the case of the internal-loop ALR with a significantly enlarged head zone, the omission of this fact could lead to serious errors in the prediction of reactor hydrodynamics. Thus, the distribution between the upper (separator) and lower (riser and downcomer) sections of the reactor has to be taken into account. As will be shown later (Figure4 and Table 2), the solids holdup in the separator is fairly constant throughout the range of air flow rates applied except for the lowest ones. Hence, the known portion of solids present in the lower reactor zone (riser + downcomer) was used to estimate the solids distribution between the main reactor sections (Equations 6 and 7).

\section{Prediction of Liquid Velocity and Gas Holdup}

The experimental and model predicted values of the riser holdup and the liquid velocity in the downcomer are depicted in Figure 2. The measurements have been carried out using two different techniques - the first one, the air flow rate was gradually increased (open symbols in Figure 2); in the second one, the flow rate was decreased until the stalling was attained (solid symbols). As can be seen, hysteresis phenomena appeared only at the lowest values of the air flow rate, in the region of the packed bed mode, while in the circulated bed regime, hydrodynamic parameters are independent of the measuring technique to reach an actual state.

For three-phase flow, three principal circulation regimes could be expected (García-Calvo et al., 1999). As it can be seen in Figure 2, only the packed bed at the lowest $U_{G c}$ values and circulated bed modes exist in this system. A suitable reactor geometry (high $A_{D} / A_{R}$ ratio ) and the low settling velocity give rise to the direct transition of the packed to the circulated bed regimes. The initialization of the circulated bed mode $\left(V_{L R}>U_{t}\right)$ appears at a lower air flow rate than the onset of the fluidized bed mode, where the positive driving force in the momentum balance equation is a necessary condition for its existence. In general, the hydrodynamic model satisfactorily predicts both gas holdup and liquid velocity in the whole range of conditions studied. The model prediction error is in most cases (approx. 90\%) within the range of $\pm 20 \%$. The onset of the circulated bed mode was also predicted with a good accuracy. 


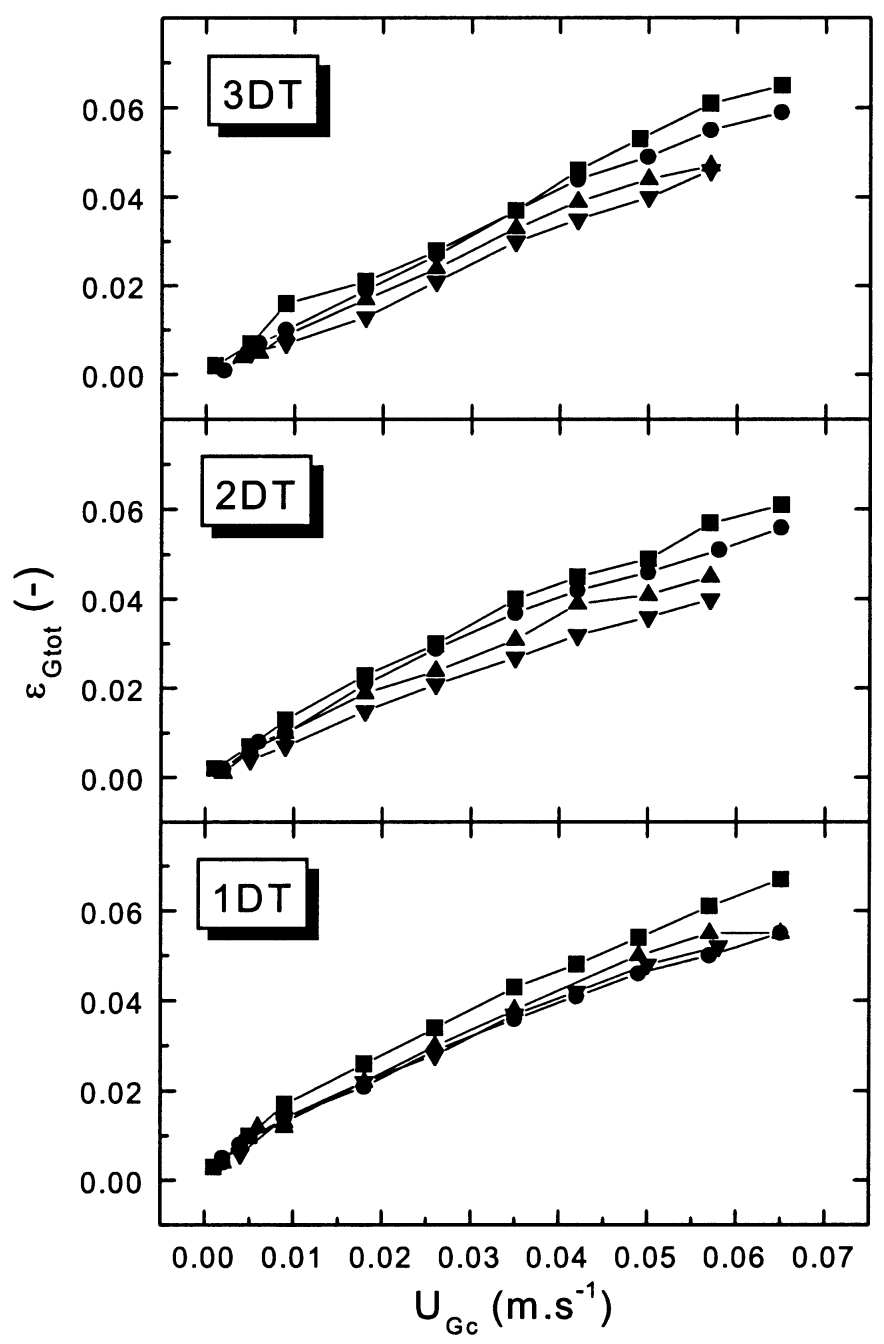

Figure 6. Total gas holdup in the column vs. superficial air velocity $U_{G c}$ with the solids loading (fStot) as a parameter. $\phi_{\text {Stot }}=0 \%(\boldsymbol{\square})$, $\phi_{\text {Stot }}=7 \%(\bullet), \phi_{\text {Stot }}=14 \%(\boldsymbol{\Delta}), \phi_{\text {Stot }}=21 \%(\boldsymbol{\nabla})$. For meanings of the labels of reactor sets 1DT. 2DT and 3DT, see Table 1.

The value of minimal gas superficial velocity, $U_{\mathrm{Cmin}^{\prime}}$ to attain the circulation of particles throughout the reactor increased with solids loading, $\phi_{\text {Stot }}$ and cross-sectional area ratio, $A_{D} / A_{R}$. Comparing different values of the draft tube to narrow column height ratios, $H_{D T} / H_{C}$ (1DT versus 2DT), a negligible effect on $U_{G \text { min }}$ was observed. A value of $A_{D} / A_{R}$ higher than 1.0 is recommended for three-phase ALR to avoid reactor stalling, especially if a very high solids loading is applied.

\section{Friction Coefficient $K_{f}$}

The friction coefficients in the riser $\left(K_{f R}\right)$ and the downcomer $\left(K_{f D}\right)$ were calculated from Equation (10), which was adapted for two-phase (G-L) flow. From this equation it is evident that the magnitude of the friction coefficient increases with the decrease of the liquid circulation velocity, $U_{L^{\prime}}$ and density, $\rho_{H^{\prime}}$ and with the increase of viscosity, $\mu_{H}$. The calculations showed no significant change of $K_{f}$ in the circulated bed mode, implying a mutual cancellation of the parameter effects, which are in fact a function of $U_{G c}$ and $\phi_{\text {Stot }}$. However, the calculation of the experimental $K_{f}$ for two- and three-phase flow by means of momentum balance equation (Equation (4)) disclosed a strong dependence on these input parameters (Figure 3).

As the amount of solids in the column increases, the friction losses increase as well. This effect is more pronounced in the ALR with higher area ratio $A_{D} / A_{R}$ (3DT), whereas no significant effect of the ratio $H_{D T} / H_{C}$ (1DT $\left.\leftrightarrow 2 D T\right)$ was found. The same effect of the solids loading on $K_{f}$ was observed in the work of Verlaan and Tramper (1987), which originates, according to the authors, from higher wall friction losses in the riser zone. These losses are caused by the displacement of particles by bubbles rising up predominately in the core of column, forcing the solid phase to be concentrated near the walls. According to Verlaan and Tramper, this is also the reason of the increase of ratio $K_{f}^{3 P} / K_{f}^{2 P}$ with an intensification of aeration. On the contrary, Bhaga and Weber (1972) and Douek (1994) pointed out the flattening of the riser velocity profile by a presence of the solid phase. As seen in the graph, the friction losses in the three-phase flow decreased as the air flow rate increased and approached to the two-phase values. This effect is coupled with the degree of homogenity of the solids distribution: at higher $U_{G c^{\prime}}$ the solids are distributed more uniformly in the column and the L-S phase is closer to a conception of pseudohomogeneous L-S phase.

A value of the friction coefficient as calculated from Equation (10) was used for all model calculations with different solids loading. However, in the context mentioned above, an incorporation of effect of the solids loading into the $K_{f}$ correlations would result in an improvement of the hydrodynamic model. In fact, taking into account the three-phase $K_{f}$ values determined from Equation (4), it was possible to obtain better prediction of the experimental data.

\section{Solids Distribution in tpal Reactor}

The experimental and model predicted values of solids holdup in the riser, downcomer and separator sections of ALR are shown in Figure 4.

\section{Effect of Gas Flow Rate and Solids Loading on Solids Holdup}

For all ALR configurations investigated, the solids holdup in the riser, $\varepsilon_{S R^{\prime}}$ decreased with the increase of the air flow rate. This decline was more pronounced with the increase of the solids loading. At the highest air flow rates, steady values of $\varepsilon_{S R}$ were attained for all solids loadings except for the highest one (21\%). As expected, $\varepsilon_{S R}$ increased with increasing solids loading. The solids holdup in the downcomer $\left(\varepsilon_{S D}\right)$ exhibited a similar dependence on the air flow rate and solids loading, however showing lower values than those obtained in the riser. On the contrary, as the air flow rate increased, the value of solids holdup in the separator zone $\left(\varepsilon_{S S}\right)$ increased slightly, reaching a plateau already at lower $U_{G c}$ values. There is one exception in the reactor 3DT with the highest solids loading, where $\varepsilon_{S S}$ increased even at the highest $U_{G c}$ values.

\section{Solids Distribution}

The solids holdup in the riser and downcomer of the ALR, $\varepsilon_{S R}$ and $\varepsilon_{S D^{\prime}}$ converged with increasing air flow rate to a constant value at the highest values of $U_{G c}$. It means that uniform distribution in the reactor (except for the enlarged head zone) was achieved for the highest values of the air flow rate. This assumption is often used in works dealing with the investigation of hydrodynamics 


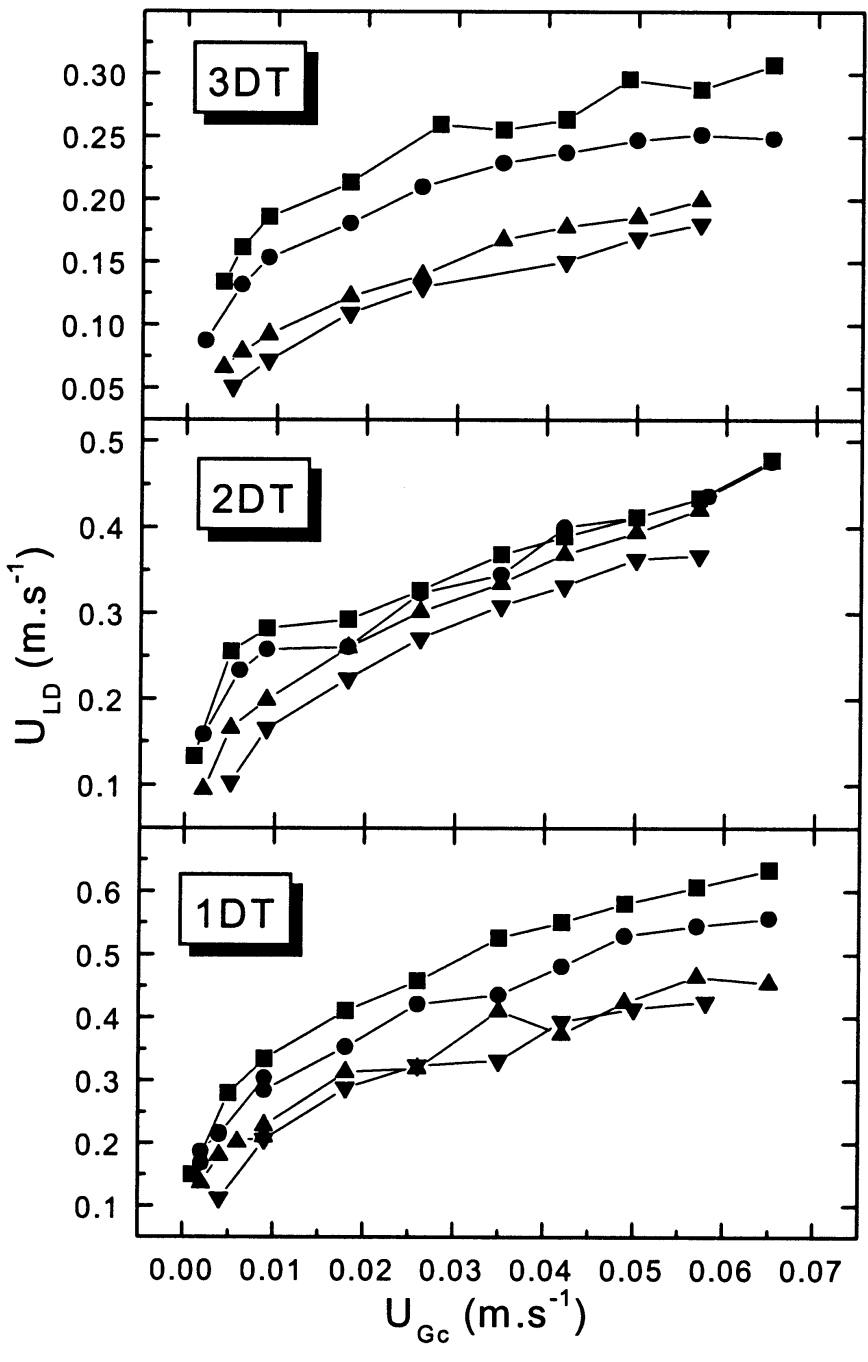

Figure 7. Superficial liquid velocity in the downcomer, $U_{L D^{\prime}}$ as a function of the $U_{G c}$ and the solids loading (fStot) as a parameter. $\phi_{S t o t}=0 \%(\mathbf{\square})$, $\phi_{\text {Stot }}=7 \%(\bullet), \phi_{\text {Stot }}=14 \%(\boldsymbol{\Delta}), \phi_{\text {Stot }}=21 \%(\boldsymbol{\nabla})$. For meanings of the labels of reactor sets 1DT, 2DT and 3DT, see Table 1.

of ALR with three-phase flow using low-density particles (Lu et al., 1995). In the present case, a homogeneous distribution of the solid phase was attained at both reactor configurations with the wide inner tube (1DT and 2DT sets); however, there are some disturbances in the solids holdup curves, making a quantification of general conclusions difficult. It can be said that the non-uniformity of solids distribution between riser and downcomer generally decrease with the gas flow rate and is not influenced by solids loading. Nevertheless, it is clearly seen that the most uniform solids distribution was achieved in the 2DT reactor set, for which eventually a homogeneous distribution of the solid phase in the whole range of the gas flow rates applied could be found at lower values of solids loading. At the solids loading of $21 \%$, this equality was attained only at $U_{G c}$ values as high as $0.05 \mathrm{~m} / \mathrm{s}$. The most uneven solids distribution was found in the 3DT reactor set.

Related to the solids distribution throughout the reactor, the solids holdup in the separator, $\varepsilon_{S S}$, was found to be markedly lower than that in the riser and downcomer sections. It confirms an efficient sedimentation of solid particles in that zone. Since the enlarged settling zone represents a large portion of the total reactor volume (from 50 to $63 \%$ ), the volume of solids located in this zone represents a very large portion of the total amount of solids in the reactor. The percentage ratio of solids volume in the separator to the total volume of solids ranged from 22 to $58 \%$ (Table 2). This means that any change of the reactor design or of its operation, even if resulting in a slight variation of the solids holdup in the separator, may provoke a significant alteration of the solids distribution in the whole reactor. One example can be seen in Table 2: simply by shortening the draft tube, a significant increase of the amount of solids in the head zone can be obtained. It can be concluded from Table 2 that for the reactor set 1DT there was no particular trend for solid phase distribution, whereas for reactor set 2DT the highest value of solids volume was found in the separator. The highest values of solids volume were observed in the downcomer for 3DT set.

\section{Prediction of Solids Holdup}

The experimental and predicted values of solid holdup in all sections of the ALR are depicted in Figure 4. In both reactors with the wide draft tube (1DT and 2DT), a good prediction of solids holdup in all sections of reactor was obtained. The solids holdup in the riser is always higher than in the downcomer but both values converged after reaching the circulated bed mode. However, the model underestimates both $\varepsilon_{S R}$ and $\varepsilon_{S D}$ in the reactor with narrow draft tube (3DT). This inaccuracy is caused by problems with the satisfactory estimation of the portion of solids present in the separator zone and the total solids holdup referred to the riser volume $\left(\varepsilon_{S}^{0}\right)$, which was very small compared to that of the downcomer and separator zones.

Establishing an analytical procedure for determination of the solids distribution in the ALR with an enlarged head zone including all reactor sections would be a task for future work. A thorough CFD modelling of the headspace of various ALRs would yield a quantification of the influence of the separator design on the reactor hydrodynamics and provide characteristic design equations suitable for the proper selection of the separator geometry.

\section{Effect of Reactor Design and Solids Loading on $V_{L}$ and $\varepsilon_{G}$ Gas Holdup}

The effect of the air flow rate and of the reactor geometrical parameters $A_{D} / A_{R}$ and $H_{D T} / H_{C}$ on the gas holdups in the riser, downcomer and separator sections is shown in Figure 5 for $\phi_{\text {Stot }}=7 \%$. Similar trends were found also for different values of $\phi_{\text {stot }}$. As can be seen, all partial gas holdups increased, as expected, in the whole range of applied air superficial velocity, $U_{G c}$. However, for $\varepsilon_{G D}$ an initial plateau was displayed due to the fact that only at higher values of air flow rate the entrainment of bubbles into the downcomer occurred. The energy demand for bubble penetration into the downcomer increased consecutively from the reactor configuration 1DT through 2DT to 3DT, indicating a negative effect of the decrease of $H_{D T} / H_{C}$ and increase of $A_{D} / A_{R}$ ratios.

In the case of the reactor set 1DT (ALR with simple separator), the downcomer gas holdup was much lower (from two to three times) than in the case of the reactor with the dual separator (2DT and 3DT set). This fact results from a distinct distribution of bubble sizes in the downcomer. In comparison with the 


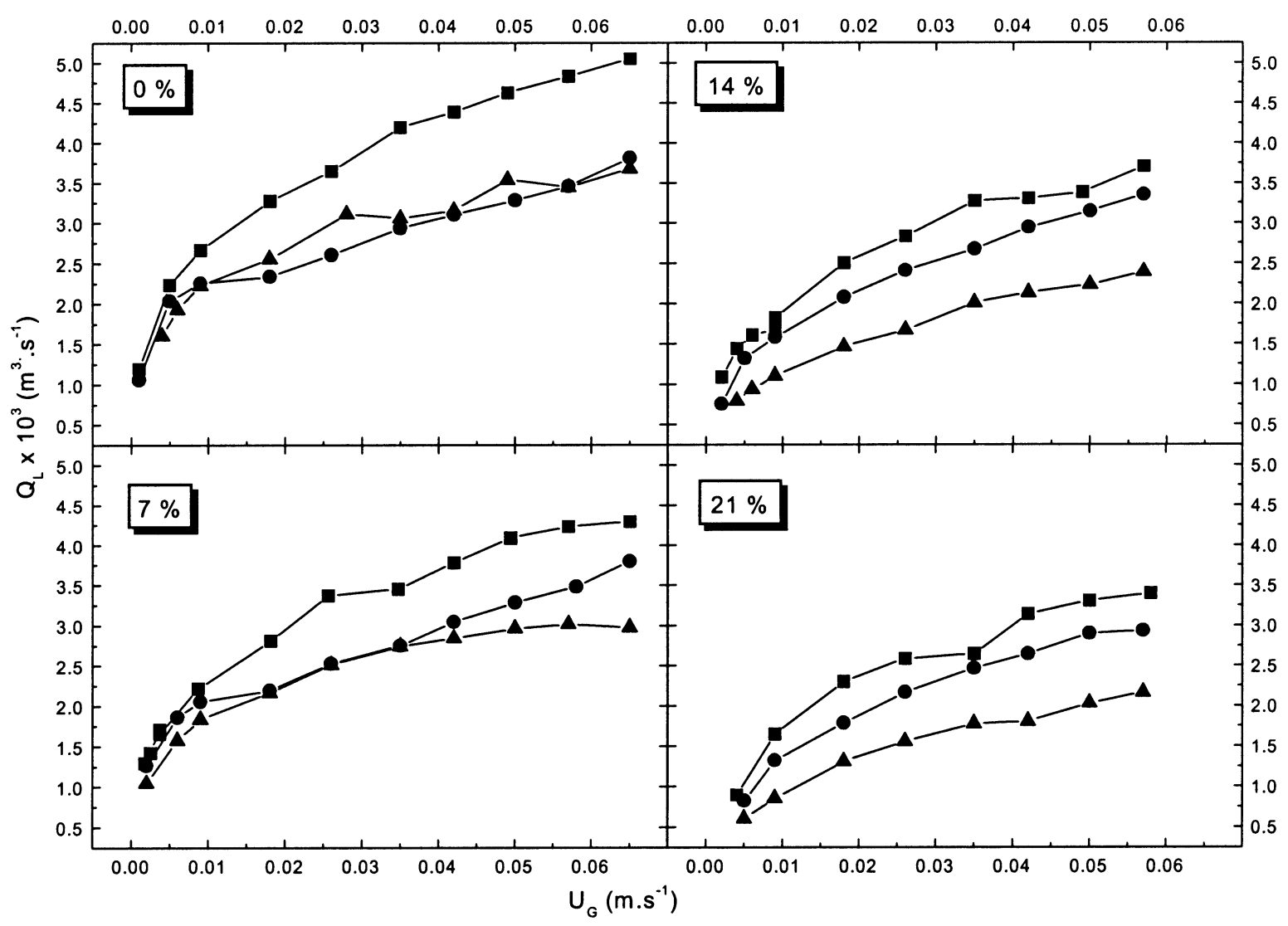

Figure 8.Average overall liquid flow rate $\mathrm{QL}$ as a function of the air superficial velocity, $U_{G^{\prime}}$ for different reactor configurations. Reactor set $1 \mathrm{DT}$ $(\boldsymbol{\square})$, reactor set 2DT $(\boldsymbol{\bullet})$, reactor set 3DT $(\boldsymbol{\Delta})$. For meanings of the labels of reactor sets, see Table 1.

reactor set with dual separator (either 2DT or 3DT), where the lower narrow part of the separator enables to drag substantial amount of bubbles of different sizes into the downcomer, only fine bubbles (with diameter of about 2-3 $\mathrm{mm}$ ) are entrained into the downcomer section at the 1DT set. In this case, there are no significant bubble coalescence events and the energy of circulation flow is high enough to recirculate most of them back to the riser. Thus, the residence time of bubbles is short, leading to very low downcomer gas holdups.

The gas holdup was also determined in the separator zone $\left(\varepsilon_{C S}\right)$, which represents a large portion of the total reactor volume. $\varepsilon_{G S}$ was found to be almost independent of the amount of solids due to a low concentration of particles in this section, even at the highest values of air flow rate. It could be observed that the bubbles rose up predominantly above the draft tube without being significantly dragged down along the walls of the separator. Thus, a large annular part of the separator is a bubble free volume. As expected from the various ALR configurations, the greatest values of $\varepsilon_{G S}$ were reached in the ALR with the highest $H_{D T} / H_{C}$ ratio. On the contrary, the smallest $\varepsilon_{G S}$ values were observed in the reactor with a wide draft tube (2DT), where more efficient bubble entrainment into the downcomer occurred compared to the column with higher $A_{D} / A_{R}$ ratio (3DT).

The total gas holdup in the reactor, $\varepsilon_{\mathrm{Ctot}^{\prime}}$ decreased with the increasing value of solids loading for all ALR configurations (Figure 6). The highest values of $\varepsilon_{G \text { tot }}$ were attained in the ALR configuration with high $H_{D T} / H_{C}$ ratio (1DT) in spite of very low values of downcomer gas holdup. This is due to the higher values of $\varepsilon_{C S}$, which contribute with a large proportion to the total gas holdup.

\section{Liquid Velocity}

The liquid velocities in the riser and downcomer were found to increase with the increase of the air flow rates, and the velocity curves showed an expected logarithmic shape. The effect of the solids loading on the superficial liquid velocity in the downcomer, $U_{L D^{\prime}}$ for all reactor configurations is depicted in Figure 7 . Concerning the linear velocity $V_{L^{\prime}}$ it was found to be independent of the solids loading despite the expected increasing bubble coalescence events and friction losses that should result in a decrease of the velocity. Nevertheless, as the solids holdup increases with increasing solids loading in the main reactor sections, the free cross-sectional area for liquid flow decreases. The magnitude of the resulting true velocity will thus be dependent of which effect will be dominant - either the decrease of the free area for liquid flux or the increase of friction losses and the decrease of the driving force. Hence, the superficial liquid velocity and the average overall liquid flow rate $Q_{L}$ was calculated from the well-known continuity equation (Livingston et al., 1993) to find out how the liquid flux varies with solids loading. Figures 7 and 8 show that a decrease of $U_{L D} / Q_{L}$ with the solids loading was observed for all reactor configurations. 
The greatest deceleration of the overall liquid circulation with the solids loading was observed at the ALR with high $A_{D} / A_{R}$ ratio as a result of the most quickly increasing friction coefficient $K_{f}^{3 P}$ (Figure 3). This is due to the fact that the increase of friction losses around the circulation loop at the bottom and top because of the flow contraction/expansion became dominant over the increasing driving force (caused not only by the reduction of the bubble penetration into the downcomer, but also by the increase of the riser gas holdup). An opposite effect of $A_{D} / A_{R}$ on $U_{L}$ was observed (Weiland, 1984), but for values of $A_{D} / A_{R}$ in the range of 0.17 to 1.7. It implies that there is an optimal $A_{D} / A_{R}$ ratio around 1 for liquid circulation and any increase/decrease of $A_{D} / A_{R}$ would worsen liquid circulation. The increase of $A_{D} / A_{R}$ on one hand increases the driving force, but also significantly increases the friction losses. On the contrary, the decrease of $A_{D} / A_{R}$ decreases the friction losses, though, it decreases the driving force as well.

Comparing the reactors with different draft tube to downcomer height ratio, $H_{D T} / H_{C}$ the increase of the height ratio has a positive effect on the liquid circulation, which was amplified by increasing solids loading. In fact, such an elongation of the draft tube is coupled with the change of the separator design as well (Figure1). This is mainly a consequence of increasing the driving force $\left(\varepsilon_{G R^{-}} \varepsilon_{G D}\right)$. It can be concluded that as the height of the draft tube is reduced (2DT_3DT), the overall fluid circulation slows down.

\section{Conclusions}

The present work showed how the design of enlarged separator by simple alteration of the diameter $\left(A_{D} / A_{R}\right)$ and height $\left(H_{D T} / H_{C}\right)$ of the draft tube in the internal-loop airlift reactor could effectively affect the hydrodynamics of three-phase flow in the ALR. The results showed similar solids distribution in the riser and downcomer; however, uniform distribution was achieved only at higher gas flow rates. A very low solids holdup in the enlarged separator zone was found, this parameter showing a low sensitivity to changes of the air flow rate.

The observations lead to the conclusion that an ALR with dual separator and an $A_{D} / A_{R}$ ratio around 1.2-2.0 can be suitable for batch/continuous high cell density systems, where uniform solids distribution, an efficient separation of particles from the liquid phase (upper part of the separator zone), and the maintenance of the bubbles inside the reactor (narrow part) is desirable. In addition, the lower part of the dual separator acts as an efficient mixer, which can significantly help to improve the overall mixing in the ALR.

A three-phase fluid model was used to predict the hydrodynamic parameters - liquid velocity, gas holdup and solids distribution data. It was shown that the model could satisfactorily describe the behaviour of a three-phase ALR with a significantly enlarged head zone, if the solids distribution between the separator and the riser/downcomer zones is known. The results of this study coupled with the model predictions may be applied to suggest optimal design (in terms of hydrodynamic behaviour) of a batch/continuous three-phase ALR for high cell density fermentations.

\section{Acknowledgements}

This research has been supported by a Marie Curie Fellowship of the European Community programme Improving Human Research Potential under contract number MCFI-2001-01504.

\section{Nomenclature}

A cross-sectional area, $\left(\mathrm{m}^{2}\right)$

$D \quad$ column diameter, $(\mathrm{m})$

$H \quad$ vertical height, $(\mathrm{m})$

$K_{f} \quad$ friction coefficient

$L_{e} \quad$ equivalent length of fittings, $(m)$

$N \quad$ liquid velocity profile parameter

$p \quad$ pressure, $(\mathrm{Pa})$

$Q \quad$ flow rate, $\left(\mathrm{m}^{3} \cdot \mathrm{s}^{-1}\right)$

$R e_{p} \quad$ Reynolds number of particle

$t$ time, (s)

$U \quad$ superficial velocity, $\left(\mathrm{m} . \mathrm{s}^{-1}\right)$

$U_{b} \quad$ bubble rise velocity, $\left(\mathrm{m} \cdot \mathrm{s}^{-1}\right)$

$U_{t} \quad$ settling velocity of particles, $\left(\mathrm{m} . \mathrm{s}^{-1}\right)$

$U_{\text {to }} \quad$ terminal settling velocity of particle, $\left(\mathrm{m} \cdot \mathrm{s}^{-1}\right)$

$V \quad$ linear velocity, $\left(\mathrm{m} . \mathrm{s}^{-1}\right)$

We $\quad$ We $=\rho_{S} U_{b}^{2} d_{p} / \sigma_{L}$

\section{Greek Symbols}

$\alpha \quad$ parameter related to two-phase flow

$\varepsilon \quad$ holdup reffered to G-L-S phase

$\varepsilon_{S}{ }^{0} \quad$ total solids holdup referred to volume of the riser

$\varepsilon_{S}{ }^{00} \quad$ solids holdup initially in the riser

$\phi_{S, \text { tot }} \quad$ solid loading reffered to L-S phase

$\mu \quad$ viscosity, (Pa.s)

$\rho \quad$ density, $\left(\mathrm{kg} \cdot \mathrm{m}^{-3}\right)$

\section{Subscripts}

$2 P \quad$ two-phase flow

$3 P \quad$ three-phase flow

atm atmosferic

c averaged at geometrical centre of column

C circulation/column

H pseudohomogeneous

$\min$ minimal

D downcomer

DT draft tube

G gas phase

$L \quad$ liquid phase

$p \quad$ particle

$R \quad$ riser

$S \quad$ solid phase

SEP separator

$T$ top

tot total

\section{References}

Bhaga, D. and M.E. Weber, "Holdup in Vertical Two and Three Phase Flow. Part I: Theoretical Analysis, and Part II: Experimental Analysis", Can. J. Chem. Eng. 50, 323-336 (1972).

Birch, J.R. et al., "Continuous Fermentation Device", in United States Patent, Celltech Limited, Slough, UK, (1988), 8 pages.

Domingues, L., M.M. Dantas, N. Lima and J.A. Teixeira, "Continuous Ethanol Fermentation of Lactose by a Recombinant Flocculating Saccharomyces Cerevisiae Strain", Biotechnol. Bioeng. 64, 692-697 (1999).

Domingues, L., N. Lima and J.A. Teixeira, "Alcohol Production from Cheese Whey Permeate Using Genetically Modified Flocculent Yeast Cells", Biotechnol. Bioeng. 72, 507-514 (2001).

Douek, R.S., A.G. Livingston, A.C. Johansson and G.F. Hewitt, "Hydrodynamics of an External-Loop Three-Phase Airlift (TPAL) Reactor", Chem. Eng. Sci. 49, 3719-3737 (1994). 
Epstein, N., "Three-Phase Fluidization: Some Knowledge Gaps", Can. J. Chem. Eng. 59, 649-657 (1981).

Freitas, C., M. Fialová, J. Záhradník and J. A. Teixeira, "Hydrodynamic Model for Three-Phase Internal- and External-Loop Airlift Reactors", Chem. Eng. Sci. 54, 5253-5258 (1999).

Freitas, C. and J.A. Teixeira, "Solid-Phase Distribution in an Airlift reactor with an Enlarged Degassing Zone", Biotech. Tech. 12, 219-224 (1998).

García-Calvo, E., A. Rodríquez, A. Prados and J. Klein, "A Fluid Dynamic Model for Three-Phase Airlift Reactors", Chem. Eng. Sci. 54, 2359-2370 (1999).

Heijnen, J.J., J. Hols, R.J.G.M. van der Lans, H.L.J.M. van Leeuwen, A. Mulder and R. Weltevrede, "A Simple Hydrodynamic Model for the Liquid Circulation Velocity in a Full-Scale Two- and Three-Phase Internal Airlift Reactor Operating in the Gas Recirculation Regime", Chem. Eng. Sci. 52, 2527-2540 (1997).

Heijnen, J.J. and K. van't Riet, "Mass Transfer, Mixing and Heat Transfer Phenomena in Low Viscosity Bubble Column Reactors", Chem. Eng. J. 28, B21-B42 (1984).

Hwang, S.-J. and W.-J. Lu, "Gas-Liquid Mass Transfer in an Internal Loop Airlift Reactor with Low Density Particles", Chem. Eng. Sci. 52, 853-857 (1997).

Klein, J., M. Bla_ej, _. Godó, O. Dolgo_ and J. Marko_, "Application of a Magnetic Tracer Method for the Characterisation of Hydrodynamics in Internal-Loop Airlift Bioreactors", Chem. Papers 54, 456-466 (2000).

Livingston, A.G. and S.F. Zhang, "Hydrodynamic Behaviour of ThreePhase (Gas-Liquid-Solid) Airlift Reactors", Chem. Eng. Sci. 48, 1641-1654 (1993).

Lu, W.J., S.J. Hwang and C.M. Chang, "Liquid Velocity and Gas Holdup in 3-Phase Internal Loop Airlift Reactors with Low-Density Particles", Chem. Eng. Sci. 50, 1301-1310 (1995).

Merchuk, J.C., N. Ladwa, A. Cameron, M. Bulmer and A. Pickett, "Concentric-Tube Airlift reactors: Effects of Geometrical Design on Performance", AlChE J. 40, 1105-1117 (1994).

Perry, R.H. and D.W. Green, "Perry's Chemical Engineers' Handbook", Sixth ed., McGraw-Hill, New York, NY (1985).
Pollard, D.J., P.A. Shamlou, M.D. Lilly and A. P. Ison, "Saccharomyces Cerevisiae Fermentations in a Pilot Scale Airlift Bioreactor Comparison of Air Sparger Configurations", Bioproc. Eng. 15, 279-288 (1996).

Sun, Y., Y.L. Li and S. Bai, "Modeling of Continuous L(+)-Lactic Acid Production with Immobilized R-Oryzae in an Airlift Bioreactor", Chem. Eng. J. \& Biochem. Eng. J. 3, 87-90 (1999).

Tobajas, M., M.H. Siegel and S.E. Apitz, "Influence of Geometry and Solids Concentration on the Hydrodynamics and Mass Transfer of a Rectangular Airlift Reactor for Marine Sediment and Soil Bioremediation", Can. J. Chem. Eng. 77, 660-669 (1999).

Verlaan, P. and J. Tramper, "Hydrodynamics, Axial Dispersion and GasLiquid Oxygen Transfer in an Airlift-Loop Bioreactor with ThreePhase Flow", in "International Conference of Bioreactors and Biotransformations", G.W. Moody and B. P.B., Eds., Gleneagles, Scotland, UK, Nov 9-12, (1987), pp. 363-373.

Vicente, A.A., M. Mota and J.A. Teixeira, "Flocculation Bioreactors", in "Multiphase Bioreactor Design", J.M.S. Cabral, M. Mota and J. Tramper, Eds., Taylor \& Francis, London, UK, (2001), 528 pages.

Vicente, A.A. and J.A. Teixeira, "Hydrodynamic Performance of a ThreePhase Airlift Bioreactor with an Enlarged Degassing Zone", Bioproc. Eng. 14, 17-22 (1995).

Weiland, P., "Influence of Draft Tube Diameter on Operation Behaviour of Airlift Loop Reactors", Ger. Chem. Eng. 7, 374-385 (1984).

Wenge, F., Y. Chisti and M. Moo-Young, "A New Method for the Measurement of Solids Holdup in Gas-Liquid-Solid Three-Phase Systems", Ind. Eng. Chem. Res. 34, 928-935 (1995).

Manuscript received November 12, 2002; revised manuscript received March 31, 2003; accepted for publication June 25, 2003. 